\title{
The role of educational technology in the development of the human resources of the SA Defence Force for the year 2000
}

Rear-Admiral R. Eberlein*

\section{INTRODUCTION}

"Just as education holds the key to the future in the new South Africa, so educational technology holds the key to the future in the SA Defence Force."

In the last few months it has become increasingly obvious that momentous changes are occurring in South Africa. From all sides of the political spectrum, political figures are making announcements and pronouncements about a "new South Africa" and the conditions which will need to be met in order to realise that ideal.

While many of the changes are occurring outside the sphere of influence of the SA Defence Force (SADF), nonetheless it is being and will be affected by those changes. One has only to think of the effects of the implementation of United Nations Resolution 435 on the role and structure of the SADF; the change in the National Service system; the release of $\mathrm{Mr}$ Nelson Mandela; the ongoing re-organisation to provide for these and the changes necessary to provide for the year 2000 and beyond to realise the magnitude of the effects of those changes on the SADF.

At the same time, and for obvious reasons, the priorities allocated to state functions and finances are changing. For many years defence was a high, if not the highest, priority of the State. Now other functions are coming to the fore and assuming greater importance and at the same time demanding a greater slice of the exchequer.

Primary among the newly emerging functions of importance is education which, together with social upliftment is destined to play an increasing role in the development towards the new South Africa.

Education is seen by some almost as a panacea, a cure-all, a means of solving problems ranging from the population explosion, through the provision of skilled workers, the reduction of unemployment to the curing of AIDS. That education has a vital and major role to play in all of these and many more areas in the development of the new South Africa is true though whether it is a panacea is still to be seen.

Education Technology or Edtech as it is more frequently called, has just such a vital and major role to play in the development of the "new" SADF, the defence force of the year 2000 and beyond.

In this paper an attempt will be made to define and exemplify the role that Edtech will need to play to ensure an effective, combat-ready SADF of the future.

\section{STRATEGY FOR DEVELOPMENT}

In an earlier paper (Militaria 20/2: p 28) a strategy for the development of the human resources of the SADF for the year 2000 was proposed. As much of the importance attached to Edtech is derived from that strategy, a brief resumé of the arguments leading to it is appropriate at this stage.

The SADF, in common with other organisations and people in the Republic, is experiencing considerable upheaval and change in the four acknowledged power bases: socio-political; economic; technological and military.

The upheaval and change manifests itself in a number of ways, ways which are sometimes not perceived as being caused by change, unless one knows where to look and what to look for.

We are aware of some of these changes, their causes and probable effects but not of others. What has become obvious in recent times is that similar changes are occurring in many different countries around the world, and that while no comparison can be drawn between changes occurring in particular countries, this phenomenon of change itself has several common characteristics.

It has been realised that these changes impinge upon and will impinge upon the ability of the 
personnel in the SADF to perform their tasks effectively, and consequently upon the ability of the SADF as an organisation to meet its primary and secondary objectives, unless steps are taken to counter or to manage the effects of change.

Faced by all this change, one needs therefore to ask:

"Will the personnel management policy and practice of the SADF be able to meet the needs of the organisation and its members in the year 2000?"

To answer this question, one needs to consider the nature of some of the changes occurring. and some of their implications.

\section{PREDICTED AND EXISTING CHANGES}

\section{Accelerating Rate of Change}

This country, indeed the world, is in a state of change. The fact of change is generally appreciated, but the fact that the rate of change is increasing (or accelerating) is not generally realised.

This accelerating change has a number of sideeffects. Too-rapid change brings with it instability, impermanence, a feeling of transience and stress (Toffler, 1970: 238). Outwardly people may not change, but in their behaviour towards others, the attitudes to their jobs and the environment, they do change and these changes can be distressing to all. Without skilled assistance people in an organisation are unable to cope with rapid change and their performance and the effectiveness of the organisation is bound to suffer.

\section{Demographic Change}

The basic facts of South Africa's demographic situation are well-documented (Gerber, Nel and Van Dyk, 1987: 31 et seq) and statistics reveal that the total population of the Republic will grow from approximately 32,1 million in 1985 to approximately 44,8 million in the year 2000 . The Black population will provide about 11,1 million of this growth, while the remaining 1,6 million will come from the remaining population groups, to make up the growth of approximately 12,6 million. This growth will need to be educated and absorbed as far as possible into the available job market.
If one considers the shortage of managerial, executive, clerical and technical skills in the Republic and that a large proportion of the relevant jobs present require a degree or diploma qualifcation, then a predicted shortage of 65000 graduates and 37000 diplomates by the year 2000 is a cause for concern. More concern is needed when one considers that there will be a surplus of more than 3 million in the educational category of Std 8-10 (Ibid: 41). The majority of these matriculants will be academically-trained in a world demanding an increasing number of technically-skilled workers. When one considers the criticism levelled at the quality of the matriculation qualification of the majority of the black population, the importance of appropriate education in the new South Africa comes more visible, as does the potential effect on the SADF.

\section{Technological Change}

Technology may be defined as that amount of information and/or skills and experience developed for the production and utilisation of goods and services. It may include the following:

(a) Scientific and technical knowledge

(b) Engineering knowledge

(c) Managerial knowledge,

used in the specification, design, development and application of the technology (Australian Government, 1980: 3).

Technological change is therefore, change in the technology (the processes, materials, machinery or equipment) which has an effect on the way the work is performed. This change also affects the people in the organisation.

The SADF has been involved in a war in which highly-sophisticated technology (hi-tech) plays a major part. Some of the equipments ranged against us in the past (and, in all likelihood, in the future) were so new and advanced, that the military people of the West had not yet had experience of them. Such hi-tech equipment calls for high levels of (especially) technical education for its development and maintenance, while lesser skills may be demanded for its operation.

In effect, the indications are that the SADF of the future will need to be able to handle a hi-tech (probably conventional) threat demanding high levels of technical expertise in a relatively small select group; and a lower technology (probably unconventional or anti-terrorist) threat demand- 
ing much lower skill levels in much larger groups of people.

Significantly, the greater portion of the skilled designers, maintainers and operators in the hitech area come from the White population, and a very small portion from the Black population (Ibid: 34$)$ with no predicted change coming.

The increasing sophistication of the weaponry needed to survive will demand higher and higher skills of the maintainers of the equipment, whose skills will become more and more essential. At the same time, economic development in the country, also essential for survival, together with technological change will place even greater demands on the very limited skilled manpower available. In some way, this need will have to be met, in a very short time, from the other population groups whose educational development does not at this time match the requirement.

\section{Change in Attachment to and Involvement with the Organisation}

An accepted norm among the majority of longserving members of the SADF is long-term attachment to the organisation (career-orientation, or long-service) and involvement with or commitment to the aims and objectives of the SADF (loyalty).

It is increasingly becoming evident that a large proportion of the younger members (and potential members) do not subscribe to either of these norms. Occupational mobility has grown to the extent that five to six different jobs in different organisations in a working lifetime, is the norm (Toffler, 1970: 106). This "serial-career pattern" has significant implications for an organisation whose entire administration pattern and reward system is based on long-service.

Of further significance is the growing tendency of the individual to be loyal to his own needs and desires, and not to the aims and needs of the organisation, unless these happen to coincide. The trades union movement too makes use of this tendency in extending its influence into areas, such as the SADF, previously immune to their activities.

\section{Productivity}

South Africa is known for a relatively low level of productivity, and several programmes for im- proving such productivity are on the go now, especially in the SADF.

Improving productivity is a complex procedure. Suffice to say that in this context education. training and development play a vital role.

\section{Change in Organisational Structure and Design}

"An armed force is a body of men organised to achieve its ends irresistibly by coordinated action" (Downey, 1977: 62). Cohesion and the need for good organisation are so demanding that the armed forces of the world have often been in the forefront of developments in organisational science.

The multiplicity of roles for which an armed force is compelled to cater is reflected in the organisation structure. In the SADF for example apart from preparing for conventional warfare on land, in the air and at sea, counter-revolutionary warfare, action in support of the SA Police, aid in case of civil disaster and so on are ongoing actions needing a organisation which is exceptionally strong but nevertheless flexible.

Over the decades an organisation structure has evolved which is both functional and modular in design and which is directed towards the man in the front line in order to motivate him, train him, equip him, and to direct his actions (Downey, 1977: 66).

Whilst under the command of a previous Chief of the SA Defence Force, a move was made towards more participative management, and the development of synergism in management. The then existing organisation was apparently still too inflexible, and there emerged a tendency to appoint "work groups", multi-disciplinary and multi-arm-of-service groups to tackle specific projects or problems. This tendency is typical of the move from a fixed bureaucratic structure to an "ad-hocracy", a flexible temporary organisation whose peripheral structure and composition changes according to the needs of the moment while retaining a relatively stable core suited to the purpose of the organisation (Toffler, 1970: 120).

\section{Changes in Organisational Culture}

While the concept of organisational culture is difficult to define, it is generally accepted that 
such a thing exists. In all organisations there are deep-set ideas and beliefs about the way an organisation should be structured, the way people should be led and managed, the way authority should be exercised, the way people should be rewarded and disciplined, the way they should dress and act, the terminology (or language used and so on. These things make up the culture of the organisation. It reflects a pervasive feeling of life, or a set of norms (Schmikl, 1988: 65). The overall culture of the SADF can be seen as being a "Role Culture" characterised by:

(a) Bureaucratic approach.

(b) Logic and rationality as the basis of decision-making.

(c) Organisation structure based on functional specialisations.

(d) Control by procedures; job descriptions; authority definitions; key performance areas; procedures for communications; rules for the settlement of disputes etc.

(e) Co-ordination at the top by a narrow band of senior managers.

(f) Individuals selected for satisfactory performance of a role. The role is so described that a number of people could fill or fit it. Performance over and above the job description is not required and can be disruptive at times.

(g) Innovative ability not fully exploited or realised. (Schmikl, 1988: 70)

An organisation's culture (especially that of a large organisation with a long history) changes only slowly. As the leadership projects its own assumptions about the cultural norms and embeds them gradually and consistently in the purpose, structures, objectives and working procedures of the organisation, so the culture will change (Schein, 1987: 317)

In the private sector from whence comes the bulk of SADF personnel (ie the National Servicemen and Citizen Force personnel), changes in the culture of organisations and the values of individuals apparently have been taking place more rapidly than in the SADF. In the future, with larger numbers of people with different cultural norms being absorbed into the SA Defence Force the impact of cultural differences is bound to become more visible. Where these cultural values differ from those of the SADF, and are not changed to meet those of the SADF, conflict occurs.

Such conflicts of culture and values have ad- verse effects on the effectiveness and efficiency of the SADF. These conflicts divert attention and effort from achieving the primary objectives of the SADF to resolving the conflicts instead.

\section{Change in Leadership Style and Management Philosophy}

Leadership style is seen as being the way in which the management philosophy is applied in practice (Gerber, Nel and Van Dyk, 1987: 100). This has an important impact on the motivation, commitment, adaptability and satisfaction of employees.

Literature on the subject boasts a wide variety of approaches to leadership, or a classification based on the theory applicable to a particular style of leadership. Schilbach (1983: 183) concludes that the situational approach to leadership propagated by Hersey and Blanchard, is the most useful to explain effective leadership. The situational approach is seen to be particularly useful in the complex environment of South African enterprises for the very reason that it is so flexible. The SADF has advocated the application of the situational approach since 1976, and is in the process of establishing it as a core skill at all leadership and managerial levels.

\section{CHARACTERISTICS OF A SUCCESSFUL ORGANISATION}

Much of the recent literature devoted to organisations emphasises the need for them to grapple with the changes occurring in the external and internal environments and to adapt the organisation to these changes in order to be successful.

The term "successful" is used here to describe an organisation which is both effective and efficient in achieving its objectives (Van Dyk, 1987: 17). This term includes the meaning ascribed to "excellence", a term also popular in the literature (Peters and Waterman, 1982: 8).

In their studies of the success of organisations world-wide, Peters and Waterman (1982: 13) and Peters and Austin (1985) identified the following characteristics as leading to success:
(a) Leadership
(b) Innovation
(c) People Orientation
(d) Objectives
(e) Commitment
(f) Action Orientation 
(g) Culture and value based

(h) Simple organisation, lean staff, decentralised execution.

\section{CHARACTERISTICS OF THE SADF AS AN ORGANISATION}

From a study executed for the SA Navy (Van Dyk, 1987), the characteristics of successful organisations as depicted in the previous paragraphs. It must be emphasised that these deductions are tentative, extrapolate the findings without verification, and would need further research for confirmation or rejection. These deductions also reflect the personal opinions of the author and not necessarily the official SADF view.

(a) Leadership: The research shows that in the main subordinates consider the leadership style and ability of leaders at all levels to be acceptable.

(b) Objectives: The research shows that the setting of objectives and the issuing of taskguidelines is successful and provides a firm baseline for the achievement of individual task objectives.

(c) Other aspects:

(i) Intrinsic motivators: Although the aspects related to leadership and objective setting, inter alia, which contribute to intrinsic motivation, are generally positive, some of those aspects related to intrinsic motivation (growth, challenge, utilisation of the abilities of the individual and so on), are not. This can have the effect of neutralising the positive aspects.

(ii) Extrinsic motivators: In general these aspects (reward system, status and recognition, accommodating organisation system) were found to be negative. This can have a negative influence on motivation, innovation, and achievement motivation.

Simplictically put, the SADF appears to have positive leadership but a less-than-satisfactory, almost punitive human resources support system. The organisation appears to be a strong bureaucracy (which limits innovation and achievement in certain areas) wherein performance tends to be commensurate with perceived norms and the reward system.

\section{THE REAL PROBLEM}

In the light of the information in preceding paragraphs, on the changes occurring and predicted, as well as the findings concerning the characteristics of successful organisations and the situation of the SADF vis-a-vis these, the earlier question can be rephrased to ask:

"Does the SA Defence Force's leadership style and management philosophy, organisation culture, values and skill-level meet the requirements for organisational success and personnel needs as predicted for the year 2000?"

Put in another way, the real problem, and the challenge for the future is to use the positive characteristics and strengths of the SADF to reverse the negative ones, to get:

"A leadership style and management philosophy;

an organisation culture and value-set; and

Human Resource Management competencies

and skill-levels which will lead to success in the year 2000."

\section{PROPOSED PLAN OF ACTION FOR DEVELOPING THE HUMAN RESOURCES OF THE SA DEFENCE FORCE FOR THE YEAR 2000}

After consideration of a variety of factors and alternatives, a plan of action was derived to enable the SADF to meet this challenge. Codenamed Project SUPERSTAR the action plan appears in simplified form at Table 1. Table 1 is a diagrammatic representation of the steps considered necessary to execute the action plan for human resources development in the SADF of the year 2000. This action flow diagram is a representation of the systems approach, and depicts the action at the first level of detail. Each of the blocks (1.0; 2.0 etc) can be analysed into greater detail as the plan develops. The lines joining the various blocks have the direction of action flow shown by the position of the arrow near the junction of the lines. The final arrow at block 17.0 indicates the start of a feedback and evaluation loop, requiring the next action to be taken at block 1.0 i.e. the start of the system.

An examination of the strategy contained in the action plan will reveal the significant role to be played by training and development (and there- 


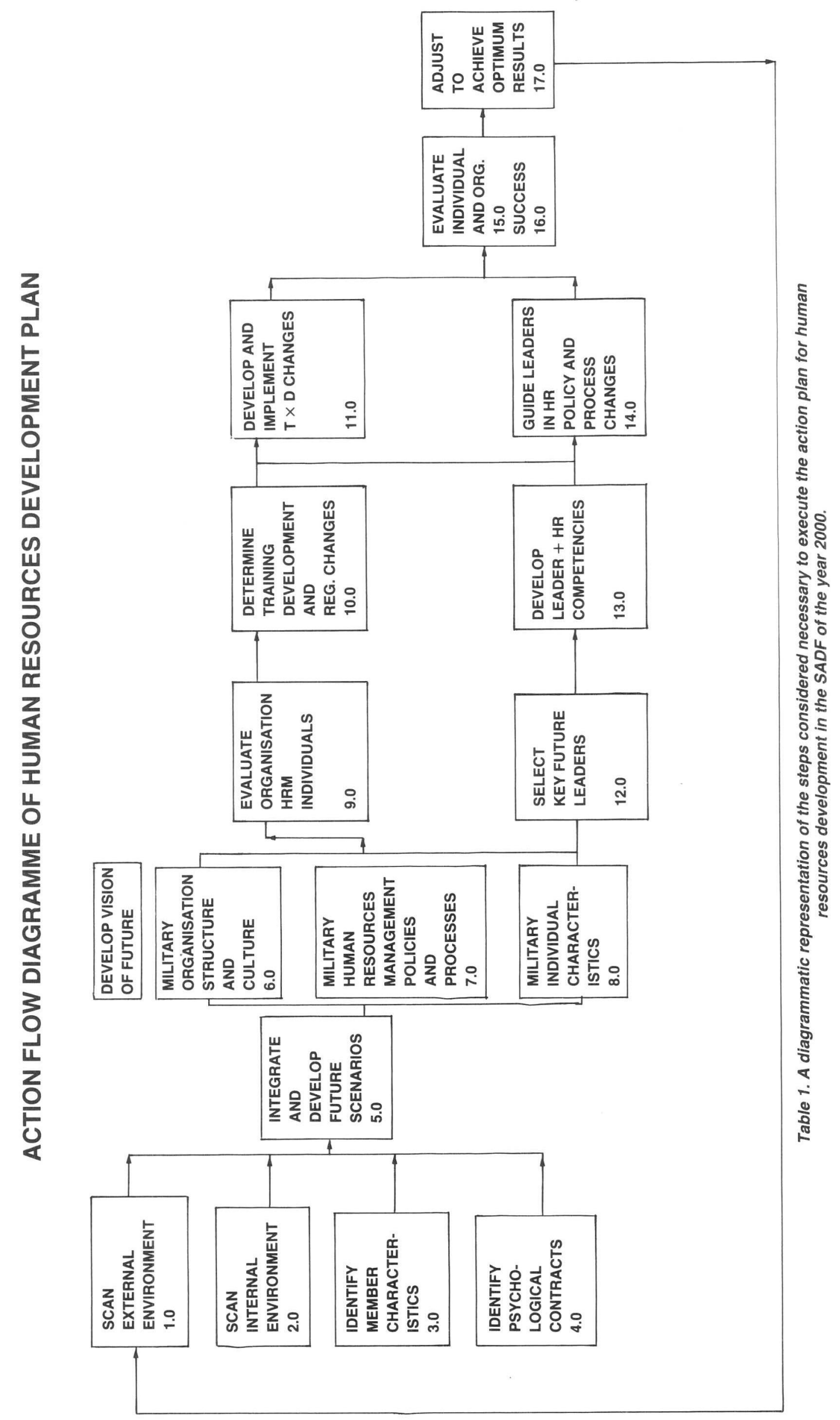


fore Edtech) in achieving the objectives. Because of this importance the other steps in the strategy will be ignored for the purposes of this paper, and attention paid only to the role of training and development.

\section{TRAINING AND DEVELOPMENT CHALLENGE}

The nub of the training and development challenge facing the SADF lies in the steps in the action plan covering:

(a) Determining training and development needs and regulation changes;

(b) Developing and implementing training and development courses; and

(c) Developing management and supervisor knowledge, skills and attitudes in key leaders.

When one considers the nature and size of the target population, their educational levels and their cultural differences, together with the types of competencies which are to be developed in them, the magnitude of the problem becomes evident. In more colloquial terms: "The mind boggles!"

The reader who is familiar with the history of the SADF over the past two decades might be tempted to say, "There's nothing different about that! We've been training people very successfully for a long time, just look at the reputation we have for producing fighting soldiers and pilots, to say nothing of the other Arms of the Service."

Such a reader would be quite correct in his assumption. The SADF has indeed produced and is producing excellent results from the existing training system, but at what cost and under what conditions?

A closer look at these latter factors reveals a very interesting situation:

(a) Over the last two decades the SADF has been the prime user of manpower in the Republic; a manpower source which has been relatively homogenous, stable and well-educated;

(b) has enjoyed a high priority in having its financial needs met;

(c) has had a relatively stable environment and clear objectives;

(d) has concentrated on training and developing the lower echelon for immediate and short-term employment in the combat and support situations; and now

(e) experiences critical shortages in the lower and middle management cadres, as well as in the technical skills arena.

As far as the existing training system is concerned, a recent survey by the SADF College for Educational Technology (COLET) ( $\mathrm{Nel}, 1989$ : 5-4) reveals a sombre picture:

(a) The term "Educational Technology" is not an established one in the SADF, and the principles of Edtech are propagated and practised on a small scale only.

(b) The SA Air Force is the only Arm of Service which makes use of the entire spectrum of Edtech development courses provided by the SADF, while the SA army (with the greatest population to be trained and developed), the SA Navy and the SA Medical Services make only limited use of these courses.

(c) The majority of instructors attend the basic Edtech course, and do not progress further.

(d) Understandably, therefore, the three most popular types of training aids in use in the SADF are précis, transparencies and flip charts, with the more modern aids such as videos and slides following on behind.

One is forced to deduce from this that the existing training system, although functioning well, is far from being optimally effective and is still centred around the instructor as the source of learning with the student primarily a spectator!

Even the sceptical reader mentioned earlier would be forced to admit that with the change in circumstances facing the SADF in the future, the chances of our retaining or exceeding the level of effectiveness of training of the past two decades, without a drastic revision of our Edtech strategy, are limited indeed!

Where then does the SADF go from here Edtechwise?

\section{EDUCATIONAL TECHNOLOGY: THE SADF APPROACH}

\section{Myth and mythology}

It is perhaps necessary at this stage to review the SADF's approach to Edtech and to clear up some of the misconceptions about Edtech. 
Edtech has developed through a number of phases, of which the first was known as the "hardware approach" and the second as the "software approach". These two approaches together form what is known today as "Technology in Education". This embraces every possible means by which information can be presented to the student. It is concerned with the gadgetry of education and development, such as the projected media, television, and language laboratories. It typifies the popular myth of what Edtech is all about, namely audiovisual aids (Percival \& Ellington, 1984: 12).

Edtech has actually grown through a third phase to maturity. This phase is sometimes jokingly referred to as the "underware approach" because it is built upon a sound foundation of learning theory. This approach made people think more carefully about all the aspects of the design, development and implementation of teaching/learning situations and not just the audio-visual implications. This in turn led to a new interpretation of Edtech as the entire technology of education, rather than the use of technology in education, with the latter being regarded merely as part of the former instead of the whole as had been the case previously (Percival \& Ellington, 1984: 12-13).

The SADF embraces the Technology of Education approach and accepts a definition of Edtech as ".... the application of knowledge, systems and techniques to the improvement of human learning" (Neville, 1977: 9).

\section{Edtech philosophy}

In that latter phrase "the improvement of human learning" lies the key concept to the principles (or philosophy) upon which the application of Edtech in the SADF is based. These are the principles which we believe are vital to the development of an Edtech strategy for the future development of the training system and ultimately the success of the SADF.

It is essential that the design, development and implementation of training and development reflects the following characteristics.

(a) Learner-centred: The learner (or student) must be the central figure around whom the entire process revolves. A learner-centred approach requires that provision be made for: (i) Active involvement of the student in the learning process:

(ii) Participation in the management of his learning;

(iii) The motivation of the student to learn using entrinsic or intrinsic means.

(iv) Individualisation of learning, to make provision for the specific abilities and needs of the student.

(b) Trainer as facilitator: The trainer (or instructor) must assume a new more complex role than in the past. Where previously the trainer was the prime source of and presenter of learning material (the "chalk and talk" approach), in the SADF approach he must play a variety of roles in the core of which is that of facilitator of learning. In this he is "a procedural technician, resource person and co-inquirer; he is more a catalyst than an instructor, more a guide than a wizard" (Knowles, 1970: 43). Van Staden (1986: 52) conceived a model of the roles of the trainer in South Africa, based on the studies of McLagan which is appropriate to the SADF. In this the principal roles of the trainer are:

(i) Mentor: An agent for the transfer of learning to the student and an instructor.

(ii) Instructor: Transfer agent, instructor and group facilitator.

(iii) Training Official: One responsible for need and task analysis; validation and evaluation of training; programme design; writing of instructional guides etc; provision of the necessary theoretical background to the training; acting as media specialist and programme administrator.

(iv) Training manager: With main roles the marketing of the training effort; determining the training strategy; and the management of training and development.

(c) Based on the Systems Approach: The Systems Approach is "essentially a way of thought, a tendency to think about problems in systems terms" (Romiszowski, 1981: 11). When applied to Edtech, it is used in instructional design, development and evaluation. It is a methodology which follows five general stages:

(i) Problem defining (in system terms)

(ii) Analysis (to generate alternatives)

(iii) Selection and synthesis of an optimal solution 
(iv) Controlled implementation

(v) Evaluation and possible revision.

(d) Competency-based: The development of the competency-based approach to defining the end-results of training was necessitated by the increasing demands being placed on the training organisation for accountability to higher management. The concept of competency in the SADF encompasses the outputs required of the learner in the job situation, and includes the skills, knowledge and attitudes needed.

(e) Modular design: A module (as used in the teaching/leaning situation) is seen as a grouping of a number of competencies into logical entities for teaching/learning purposes. A training course might consist of a number of modules to be mastered by the student. The selection of one or a number of modules, the sequence of learning and the progress from one to the next, form part of the management of the learning process in which both the learner and student participate.

(f) Technologically balanced: It is accepted that there must be a balance between the interests of the student and the demands of technology in the teaching/learning situation. By retaining such a balance, one ensures that the learners are not treated like "impersonalised battery hens" but as a "people with inquiring minds who thrive on intellectual stimulation and human contact" (Percival \& Ellington, 1984: 11) while at the same time ensuring that competencies can be developed in the most efficient manner.

(g) Balance between theory and practice: A balance between theory and practice is necessary to ensure that the student not only is competent on completion of the training course (or relevant modules) but that he is able to adapt his competency to new situations which must inevitably occur as the effect of accelerating change are felt. The concept of "learning to learn" is contained within this balance between theory and practice.

(h) Evaluation of success: An integral part of the systems approach is the constant use of evaluation to measure the success of the components of the system. Evaluation is then used as feedback to make the corrections necessary to ensure that all the components of the system meet their objectives.
Obviously evaluation includes evaluation of the learner, the trainer, and the other components of the teaching/learning situation.

\section{Responsibility for Edtech and Training in the SADF}

In the SADF as in most other organisations the responsibility for the execution of training rests with the line (as opposed to staff) functionary while overall training policy is formulated by the headquarters organisation. In practice this means that the Personnel Division of the Chief of the SADF (CSADF) sets up the policy for training and development (including Edtech) and the execution is left to the Arms of Service. Policy regarding certain aspects of the development of specialist functional groups (e.g. finance) is delegated to the responsible functional Chief of Staff.

\section{THE ROLE OF EDTECH}

To return to the question of "Where does the SADF go now Edtech-wise?" It should be obvious by now that alone and unaided Edtech can do very little to meet the needs for human resources management competencies and for skill-levels needed for success in the year 2000 and beyond. Of what use is a video programme on (to be ridiculous for a moment) electronic valve technology when thyristors (or something equally exotic) are the "in-thing" of the future? Why bother to develop a computer-based trueto-life driving simulator for a Ratel when something simpler and less expensive might just do the job?

In order to play its proper role, Edtech needs to be an integral part of an overall human resources development strategy aimed at meeting the needs of the year 2000 and beyond. The development of that human resources strategy is beyond the scope of this paper, and is in any case part of Project SUPERSTAR.

What can be addressed here though is the Edtech strategy that the SADF will follow in the future.

\section{SADF Edtech Strategy}

COLET is the key instrument for the development and implementation of the SADF Edtech strategy and has recently been through an exer- 
cise aimed at defining that strategy. The term "exercise" does not really do justice to what was done, and the end product. A debt of gratitude is owed to the Officer Commanding of that unit and his staff. Well done!

The essence of the Edtech strategy, and therefore the role of Edtech in human resource development in the SADF is "to establish within the SADF and within the parameters of the overall human resources strategy, the training, development and educational expertise needed to support the combat readiness of the SADF."

Because attitudes are important in the teaching/ learning situation, the term "expertise" is taken to mean not only knowledge and skills but also the attitudes needed to establish and apply the expertise.

Words are very important when describing what one is trying to achieve, therefore one must realise that the word "establish" is used in the stronger context of "ensuring that it becomes an inherent part" of the functioning of the SADF. Perhaps the Afrikaans word "vestig" is more descriptive here.

Recently there has been a move to re-introduce as part of the human resources function the responsibility for organisation development, and the development of skills in this area as part of Edtech. In the SADF this has not yet been done, so the development of organisational development skills remains outside the Edtech strategy.

In simple terms, the Edtech strategy aims at developing Edtech expertise on the ground in the SADF backed-up by expertise at COLET, to enable the line men responsible for training and development in the Arms of Service to get on with the job.

\section{Components of the Edtech Strategy}

Going back over the material covered earlier in this paper one can deduce a number major facets which need to be taken into account in deriving the components of the Edtech strategy.

To begin, in an examination of the teachinglearning situation which is the nucleus of any Edtech strategy, one concludes that an almost dichotomous situation exists:

(a) The Learner: Simplistically put, there are two major groupings of learner: a small group with relatively high levels of literacy, education and technological ability; and a larger group with relatively low levels of literacy, education and technological ability.

(b) The Learning Objectives (Competencies): Once again, simplistically put, there exist a relatively small group of competencies at the upper ends of the scales describing cognitive, psycho-motor and affective learning objectives to cater for the hi-tech and high level management and leadership competencies needed; and a relatively large group of competencies at the lower ends of the learning objectives to cater for the more labour intensive tasks needed in the implementation of combat and support related functions.

(c) The Trainer: From the work done by COLET it is obvious that by far the largest group of trainers are at the bottom end of the scale of Edtech competencies ("spray and pray stage") while an extremely limited number can really be considered to be Educational Technologists in the true sense of the word.

(d) Other Aspects: The other aspects needing consideration in the development of an Edtech Strategy include:

- Training Facilities (Classrooms, buildings and so on)

- Media (training aids, simulators etc)

- Methods (the teaching-learning methods such as lectures, lessons, discussion groups etc)

- Time

- Cost

These aspects are largely related to the first three, and can be summed up in the words of the Officer Commanding COLET "The term 'Educational Technology' is not an established one in the SADF, and the principles hereof are propagated and applied on a small scale only" ( $\mathrm{Nel}$, 1989: 5.4) (Own translation).

The Edtech strategy derived from the various factors has given main components supported by personnel and logistic support plans. The Officer Commanding COLET will notice my deviations from his original strategy and the changes of emphasis, both of which we have discussed, and no doubt make the necessary adjustments.

(a) Marketing Component: Two levels of marketing are involved viz the micro and the macro levels. The micro level refers to the marketing of COLET as a college and the 
seat of Edtech in the SADF; while the macro level refers to COLET's responsibility for the marketing of Edtech as a discipline and its potential contribution to the achievement of the objectives of the SADF. The marketing component of the strategy is based on aggressive marketing of the delivering high quality goods and services by COLET to clients, and on the vital role which the college can and must play in achieving the objectives related to winning the war, and ensuring effective training in the SADF. An important part of this component is the use of facilities at COLET for other purposes, including for example the development of communication, negotiation, and television interviewing skills in order to focus attention on the results which can be achieved by the use of Edtech.

(b) Research and Development Component: Research and development aims at identifying COLET as the "clearing house" for Edtech in the SADF. In this role it is intended to:

Develop the theoretical and practical basis of Edtech at the college to the level required of a consultant;

develop a network of Edtech expertise among SADF and other Educational Technologists in support of the clearing house role;

co-ordinate SADF projects in the Edtech field; and

to concentrate research and develop on those areas of the teaching/learning situation which will benefit the SADF most in the shortest possible time, with especial reference to the new technologies and the use of the computer in training.

(c) Training Component: The training component concentrates on the following areas:

The development of trainers in the four main roles spelled out earlier, ie mentor, instructor, training official, and training manager with the emphasis on providing for the dichotomous aspects of the teaching/learning situation;

the implementation of the Edtech strategy and the philosophy with its emphasis on modular and competency-based training;

the development of the particular competencies needed for the development of technical skills and the related educational background;

the development in trainers of the compe- tencies needed to adapt to new technologies, especially the use of the computer in training; and

the optimal deployment, employment and development of trainers in the SADF.

(d) Training Material Component: The findings discussed earlier indicate that the greatest need for training materials lies presently in the more conventional materials. Since the majority of units have media centres, the training material component will concentrate on:

Developing independent media centres at units, capable of meeting the unit's own requirements;

developing in the media centre personnel the skills needed to administer the centres and produce transparencies, slide-tape productions and printed materials;

producing high-quality materials outside the scope of unit media centres or for units without media centres, including transparencies, slide-tape productions, diagrams and models;

providing a consultant service aimed at integrating and optimising the use of training materials in the particular teaching/learning situation as part of the overall Edtech strategy.

(e) Television Component: The production of successful educational (training) television programmes is not only expensive in terms of equipment, but equally so in terms of the skills needed for production. The television component therefore concentrates on:

Producing at the maximum capacity of which the equipment and personnel are capable, in order to remain cost-effective; producing materials to meet the needs of the clients;

developing the expertise needed to cope with developments in the use of educational television in the field of competency-based training, and

providing a consultant service aimed at integrating and optimising the use of television in the particular teaching/learning situation and as part of the overall Edtech strategy.

\section{CONCLUSION}

In this paper an attempt was made to define the role that Edtech must play in the development of 
the human resources of the SADF for the year 2000 and beyond.

The strategy for the development of the human resources of SADF formed the basis for a discussion of the role of Edtech. Here the effects of predicted and existing changes on the SADF especially its organisation, culture and success were mooted. The need for the SADF to develop a leadership style and philosophy, an organisation culture and value-set, and human resource management competencies and skill-levels which would help to ensure that it became a successful organisation in the year 2000 and beyond, was then derived.

The plan of action developed to guide the development of the human resources of the SADF into the next century was based on the strengths of leadership, training and development and regulations extant.

Leaving aside the development of leaders and the use of the regulations, attention was focused on the training and development challenge, and the role that Edtech needed to play in this.

The SADF approach to Edtech was then discussed, and the Edtech philosophy explained.

From this was derived the Edtech strategy (and therefore the role) needed to meet the training and development challenge. In essence this strategy, with COLET. as the instrument for its implementation, involves:

the positioning of COLET as a clearing house and consultancy for Edtech-related projects and tasks:

the marketing of the role and need for Edtech in meeting the objectives of the SADF;

the development of expertise in the management and provision of training materials at unit level throughout the SADF;

the managing of the application of Edtech in the SADF to take advantage of present and future developments in the field and to serve the needs of the SADF.

\section{A FINAL WORD}

Educational Technology perhaps presently the Cinderella of training and development is all set to step into the magic coach and fulfil its true role. All that is needed is for someone to wave the magic wand!

\footnotetext{
* Rear-Admiral R. Eberlein S.D. DEd is Chief-Director Manpower Provisioning and Development, SADF.
}

\section{Bibliography}

1. Aguilar, F.J. 1967. Scanning the business environment. Macmillan: New York.

2. Australian Government, 1980. Report of the Committee of Inquiry into Technological Change in Australia, vol. 1.

3. Downey, J.C.T. 1977. Management in the Armed Forces. McGraw-Hill, London.

4. Eberlein, R. 1989. A Strategy for the Development of the Human Resources of the SADF for the year 2000. A paper presented at the Convention of the Institute of Personnel Management (SA), November 1989.

5. Gerber, P.D., Nel, P.S., and Van Dyk, P.S. 1987. Human Resources Management. Southern Book Publishers: Johannesburg.

6. Knowles, M. 1984. The adult learner: a neglegted science. Euston: Golf Publishers.

7. Koontz, H., and O'Donnel, C. 1976. Management. McGraw-Hill. Kogakusha, Tokyo.

8. Nel, J.P. 1989. Ontwikkeling van 'n bedryfstrategie vir SAW Kollege vir Opvoedkundige Tegnologie. Pretoria, KOLOT.

9. Neville, C. 1977. The Role of Educational Technology in Teacher Education. London: Councuil for Educational Technology.

10. Percival, F. \& Ellington, H. 1984. A Handbook of Educational Technology. London: Kogan Page.

11. Peters, T. and Austin, N. 1985. A Passion for Excellence. Collins, London.

12. Peters, T. and Waterman, R.H. 1982. In Search of Excellence. Harper and Row: New York.

13. Schein, E.H. 1985. Organizational Culture and Leadership. Jossey-Bass: San Francisco.

14. Schilbach, C. 1983. Die ontwikkeling van leierskapvaardighede by middelvlakbestuurders. Unpublished DCom thesis, University of Pretoria.

15. Schotz, C. 1987. Corporate Culture and Strategy - The Problem of Strategic Fit, in Long Range Planning Vol 20. No. 4.

16. Schmikl, E. 1988. Establishing an effective and efficient corporate culture. Seminar documentation, University of South Africa.

17. Tichy, N. 1983. The essentials of strategic change management, in The Journal of Business Strategy, 3(4): 55-67.

18. Tiffin, J. and McCormick, E.J. 1968. Industrial Psychology. George Allen and Unwin, London.

19. Toffler, A. 1970. Future Shock. Pan Books, London.

20. Van Dyk, P.S. 1987. Die ontwikkeling van 'n organisasie-ontwikkelingstrategie vir die SA Vloot. Unpublished DCom thesis, University of South Africa.

21. Van Staden, P.J. 1986. 'n Model vir die identifisering van bekwaamhede vir die opleiding van opleiers in Suid-Afrika: Ongepubliseerde M Phil tesis, Randse Afrikaanse Universiteit, Johannesburg. 